\title{
EDITORIAL
}

\section{Respiratory critical care HERMES syllabus: defining competencies for respiratory doctors}

\author{
Antonio Artigas, Paolo Pelosi, Dominic Dellweg, Laurent Brochard, Miguel Ferrer, Jens Geiseler, \\ Anders Larsson, Stefano Nava, Paolo Navalesi, Julie-Lyn Noël, Stylianos Orfanos, Paolo Palange, \\ Bernd Schoenhofer, Theodoros Vassilakopoulos and Anita Simonds, the ERS Educational Task Force \\ on Respiratory Critical Care HERMES
}

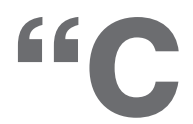

oming together is a beginning, staying together is progress and working together is success."

Henry Ford (1863-1947).

From a medical perspective, European countries are growing closer together. An increasing number of physicians are crossing borders and swapping workplaces. In order to facilitate this development, the European Union (EU) adopted a directive dictating the equality of diplomas and medical board certificates within the EU [1]. Despite a number of initiatives, such as the "Lifelong Learning Programme: education and training opportunities", for which the ERASMUS (European Region Action Scheme for the Mobility of University Students) is a subprogramme aimed at harmonising medical education during the early phases of medical training [2], there is a need to standardise knowledge and skills at later career stages in order to guarantee and harmonise the quality of patient care in Europe.

To address this, the HERMES project (Harmonised Education in Respiratory Medicine for European Specialists) was launched by the European Respiratory Society (ERS) in 2005 in order to harmonise education and training in respiratory medicine. With the success of this project, the ERS extended its scope to include a Paediatric Respiratory Medicine HERMES and subspecialty-focused HERMES projects. Thus, the Respiratory Critical Care HERMES project was launched in 2009. The project aims to provide educational standards and a training framework for respiratory critical care medicine using standardised modified Delphi surveys, facilitated group discussions and plenary sessions.

This is consistent with the ERS mission and has the ultimate goal of providing better patient care.

Similar projects in critical care have been launched in the past, such as the multi-society task force on competencies in pulmonary and critical care medicine reported by BUCKLEY et al. [3] in 2009 and the development of core competencies for an international training programme in intensive care medicine as outlined by BION and BARRETT [4] in 2006. Our aim, however, was to focus on respiratory critical care medicine and,

For affiliation details for all the authors, please refer to the Acknowledgements section.

CORRESPONDENCE: A. Artigas, Critical Care Center, Sabadell Hospital, Corporació Sanitaria Universitaria Parc Tauli, Universitat Autonoma de Barcelona, Spain. E-mail: aartigas@tauli.cat compared to our American task force counterparts, we face the challenge of harmonising an educational programme in a multitude of countries with major differences in respiratory critical care training and certification standards.

\section{NATIONAL DIFFERENCES ACROSS EUROPE}

During the Respiratory Critical Care HERMES project, a survey of country-specific information and further discussions showed that the comprehensive employment of medical techniques differed markedly between countries. Technical advances in the treatment of critically ill patients such as extracorporeal membrane oxygenation, interventional lung assist, and more advanced ventilator techniques have led to a cost explosion and have increased the financial burden for healthcare providers. Differences in financial and operational effectiveness among European healthcare systems result in a variable availability of these techniques in the respective countries. While developing the syllabus, the task force had to make decisions between the conflicting priorities of training quality on the one hand and country specific availability of techniques and resources on the other.

\section{HISTORICAL PERSPECTIVE OF RESPIRATORY CRITICAL CARE}

Intensive care medicine has many roots. The anaesthesiologist Bjorn Aage Ibsen (1915-2007) is generally considered one of the founders of intensive care medicine. He was involved in managing the poliomyelitis outbreak in Denmark in 1952 [5]. Following the failure of negative pressure ventilation in patients with bulbar poliomyelitis, the systematic use of positive pressure ventilation in these polio patients has been considered the birth of intensive care medicine. During the next two to three decades, intensive care units were mainly managed by anaesthesiologists. However, in North America it became clear that physicians with training in internal medicine or its subspecialties can very effectively deliver respiratory intensive care. Among them, pulmonary physicians had an excellent track record [6]. Intensive care and respiratory medicine intersect in the management of respiratory failure, and the treatment of severe respiratory failure should be the specific focus of respiratory critical care medicine.

Subsequently, a paradigm shift occurred in that ventilation is not only used to keep critical patients alive, but that ventilation techniques may positively affect outcomes. This placed special emphasis on respiratory critical care medicine. Advancements 
in ventilator techniques and the emergence of noninvasive ventilation have reinforced the need for specialised respiratory critical care units on an intermediate care level.

\section{BETTER OUTCOMES FOR PATIENTS}

Critical care is defined as the specialised care of patients whose conditions are life-threatening and who require comprehensive care and constant monitoring, usually in the setting of intensive care units. Most of the patients treated in the intensive care units require invasive or noninvasive mechanical ventilation, due to direct or indirect pathologies affecting the respiratory function. Current evidence indicates that patient outcomes are better when patients are cared for by trained intensivists [7]. In Europe, this can be achieved by facilitating the acquisition of agreed common competencies by trainees from the various primary specialty training programmes involved in intensive care medicine. Presently, different types of organisation for intensive care medicine are represented in Europe [8]. In many European countries, intensive care medicine is part of the training in anaesthesiology, in others it can be practised as a subspecialty, i.e. a "particular qualification" common training programme for specialists after board certification in a variety of base disciplines (anaesthesiology, cardiac surgery, cardiology, internal medicine, neurology, neurosurgery, paediatrics, respiratory medicine and surgery). In a few others, intensive care medicine is accepted as a primary speciality. One should note that according to the European directive on recognition of professional qualifications, intensive care medicine is not identified as a primary medical specialty [9]. It is our opinion that doctors with various relevant backgrounds and common formalised additional training should work together for the benefit of each individual patient and the improvement of quality of intensive care medicine.

\section{DEVELOPING A RESPIRATORY CRITICAL CARE TRAINING PROGRAMME}

Intensive care medicine was the first scientific discipline in Europe to develop a multidisciplinary training programme based on the acquisition of competencies: clearly defined sets of knowledge, skills, attitudes and behaviour, which together define the basic abilities of an "intensivist". The Competency-Based Training in Intensive Care in Europe (CoBaTrICE) project and training programme (www.cobatrice.org), supported by a grant from the European Community's Leonardo Programme, undertook an international survey of training in adult intensive care medicine and, using consensus techniques, defined the core (minimum) competencies required of a specialist [10]. We believe that this should be considered as an acceptable curriculum to be used for certification as an intensive care medicine physician in Europe. However, respiratory critical care should not be confused with intensive care medicine. It may be considered as: 1) part of intensive care medicine, specifically dealing with specific respiratory problems; or 2) part of respiratory medicine, specifically dealing with respiratory failure which does not need direct access to general, medical or surgical intensive care units.

In Europe, the respiratory medicine speciality training includes, at different levels of competence, knowledge of treatment of acute respiratory care, noninvasive mechanical ventilation and general principles of intensive care. During the Delphi I round of the Respiratory Critical Care HERMES project, an additional survey was sent to all national respondents to identify how respiratory critical care training is currently managed in their individual countries. Survey responses were received from 18 European countries, where a common theme was evident. Often, respiratory critical care medicine is taught as a subspecialty of pulmonology or respiratory medicine in general or internal medicine, and not a specialty of its own. Training periods vary in length between 3 months and 1 yr. However, it was noted that, in some countries, respiratory critical care medicine is not a stand-alone field or subspecialty [11]. The intention to develop a syllabus and a curriculum defining educational and training in respiratory critical care is therefore important.

We can define different individuals in the field of respiratory medicine, as follows. 1) Physicians specialised in respiratory medicine, working in general intensive care. These professionals should be fully considered as intensive care medicine physicians and are thus trained accordingly. 2) Physicians specialised in respiratory medicine, working in intensive care and specifically dedicated to the treatment of respiratory diseases. 3) Physicians specialised in respiratory medicine, with a particular competence for chronic respiratory problems, mainly related to noninvasive ventilation, long-term mechanical ventilation and pulmonary rehabilitation. 4) Physicians specialised in respiratory medicine, working in general wards who have developed a few specialised beds in the ward for the treatment acute respiratory critical care problems.

In the first case, we believe that a specific certification as intensive care medicine physician should be achieved through an individual training in intensive care medicine for at least 2 yrs according to the CoBaTrICE recommendations [12]. This is in line with the proposal that intensive care medicine should be a supra-speciality and not an independent speciality. In the other cases, the development of the Respiratory Critical Care HERMES project could play an important role. First, it defines the level of competence for adult respiratory physicians not directly involved in multidisciplinary critical care but who need knowledge on respiratory critical care. Secondly, it could represent the first step in developing a European diploma in respiratory critical care open to all physicians specialised in adult respiratory medicine and dealing with intermediate respiratory intensive care units or specialised units dedicated solely to critical care of pulmonary diseases. It must be emphasised that the competencies suggested by the Respiratory Critical Care HERMES are not sufficient for general, medical or surgical intermediate intensive care units, but could be used as a step-up process with an additional year required to acquire competence for multidisciplinary critical care after respiratory critical care.

A variety of different imperatives underpin the development of European educational standards as well as a training programme for respiratory critical care catering for adult respiratory medicine physicians: 1 ) harmonisation of education and training; 2) improved basic knowledge of new technologies continuously evolving in respiratory medicine; 3 ) increase of different types of patients requiring noninvasive mechanical ventilation and supportive treatment after discharge from high level general intensive care units or general, medical or surgical intermediate intensive care units; and 4) improved basic knowledge of acute critical care to facilitate interaction with other specialists. 


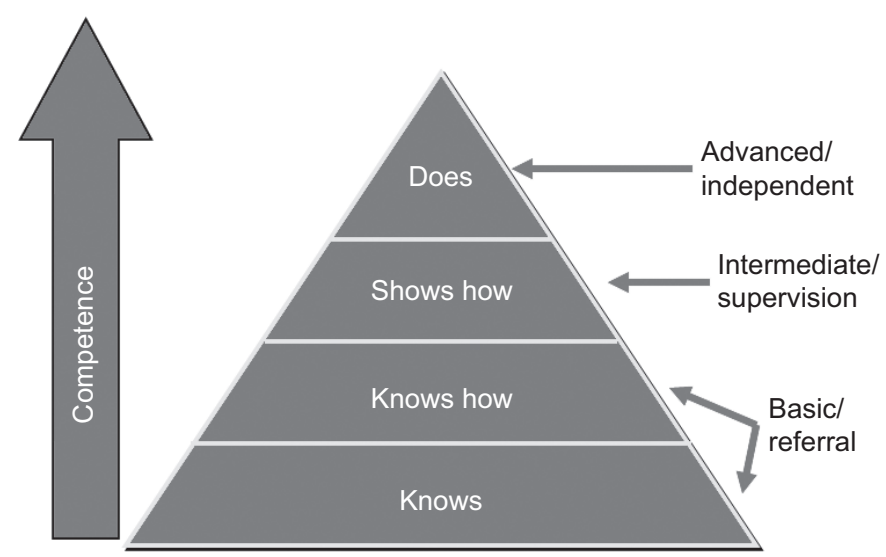

FIGURE 1. Levels of competencies in respiratory critical care medicine, categorised according to the Miller model competence. Adapted from [18] with permission from the publisher.

New technical opportunities are continuously evolving and becoming available, thus requiring more advanced knowledge. It is necessary that training in respiratory medicine includes knowledge of these techniques, such as noninvasive ventilation. Over the past decade, the number of patients requiring noninvasive ventilation has dramatically increased, both for acute ventilatory failure and also for long-term use. This is due to different factors, among them: 1) clear evidence that avoiding endotracheal intubation for respiratory support may lead to better outcomes and reduced costs; 2) the high incidence of chronic lung diseases; and 3) the increased age of patients requiring different medical and surgical treatment. It is crucial that respiratory medicine specialists are involved in this treatment specifically (i.e. ventilatory assistance). Therefore, establishing specific competencies for respiratory critical care identifies educational goals with these new developments for trainees and should guide practitioners in their life-long learning.

\section{RESPIRATORY CRITICAL CARE HERMES}

A task force composed of representatives from different European countries and disciplines convened to identify and define specific competencies for respiratory critical care. Starting with a detailed list of existing competencies of critical care medicine from various sources and following the methodology used in the HERMES projects [13-17], the task force then selected and categorised each item into three levels of competence, these being level 1: referral level; level 2: supervision level; and level 3: independent practice, based on the Miller model of competence [18], as adapted and described in figure 1 .

Each item was reviewed by the task force members individually in facilitated group discussions. Nominal group method was used for most items to retain the views and opinions of the minority perspective. Controversial items underwent additional whole group discussions with iterative (three rounds of surveys) modified Delphi techniques. Consensus was ultimately determined by a $70-80 \%$ agreement. Table 1 shows the syllabus modules.

\section{CONCLUSIONS}

Intentionally, the task force was composed of a representative mixture of physicians with different training backgrounds. The

\begin{tabular}{ll} 
TABLE 1 & $\begin{array}{l}\text { Respiratory Critical Care HERMES syllabus } \\
\text { modules }\end{array}$ \\
\hline Module & \\
\hline $\mathbf{1}$ & Respiratory physiology and pathophysiology \\
$\mathbf{2}$ & Respiratory failure \\
$\mathbf{3}$ & Respiratory medical and surgical conditions \\
$\mathbf{4}$ & Ventilation and airway management \\
$\mathbf{5}$ & Other respiratory therapies \\
$\mathbf{6}$ & Cardiovascular disorders \\
$\mathbf{7}$ & Renal disorders \\
$\mathbf{8}$ & Central nervous system disorders \\
$\mathbf{9}$ & Metabolic and endocrine effects in critical illness \\
$\mathbf{1 0}$ & Infectious diseases \\
$\mathbf{1 1}$ & Acute haematological and oncological disorders \\
$\mathbf{1 2}$ & Acute gastrointestinal and abdominal disorders \\
$\mathbf{1 3}$ & Environmental hazards \\
$\mathbf{1 4}$ & Immunology and transplantation \\
$\mathbf{1 5}$ & Monitoring, quality control and biostatistics \\
$\mathbf{1 6}$ & Practical skills \\
$\mathbf{1 7}$ & Management \\
$\mathbf{1 8}$ & Communication and ethics \\
$\mathbf{1 9}$ & Research and evidence based medicine \\
\hline &
\end{tabular}

Respiratory Critical Care HERMES project demonstrated the value of collaboration between physicians dealing with respiratory critical care coming from different experiences, training and education in respiratory medicine. Specific competencies in respiratory critical care can be identified and defined using a multidisciplinary collaborative approach. These recommendations serve as a starting point and set the stage for future modifications to ensure the maximum quality of care as the specialties evolve. Ultimately, this initiative will support the ERS mission of alleviating suffering from respiratory disease and promoting lung health.

\section{STATEMENT OF INTEREST}

Statements of interest for A. Simonds and L. Brochard can be found at www.erj.ersjournals.com/site/misc/statements.xhtml

\section{ACKNOWLEDGEMENTS}

This is the accompanying editorial to the Respiratory Critical Care HERMES: a European core syllabus in respiratory critical care medicine, published in Breathe 2012; 8: 217-229.

The authors' affiliations are as follows. A. Artigas: Critical Care Center, CIBER Enfermedades Respiratorias, Sabadell Hospital, Corporació Sanitaria Universitaria Parc Tauli, Autonomous University of Barcelona, Barcelona, Spain; P. Pelosi: Dept of Surgical Sciences and Integrated Diagnostics, IRCCS AOU San Martino - IST, University of Genoa, Genoa, Italy; D. Dellweg: Respiratory and Critical Care Medicine, Kloster Grafschaft, Schmallenberg, Germany; L. Brochard: Hopital Cantonal Universitaire de Genève, Geneva, Switzerland; M. Ferrer: Servei de Pneumologia, Hospital Clinic, Villarroel, Spain; J. Geiseler: Chefarzt Klinik für Intensivmedizin und Langzeitbeatmung, Asklepios Fachkliniken München-Gauting, Gauting, Germany; A. Larsson: Hedenstierna Laboratory, Uppsala University, Uppsala, Sweden; S. Nava: Respiratory and Critical Care, Sant' Orsola Malpighi Hospital, Bologna, Italy; P. Navalesi: Università del Piemonte Orientale "A. Avogadro", Dipartimento di Medicina Traslazionale, Novara, and SC Anestesia e Rianimazione, Ospedale Sant'Andrea (ASL VC), Vercelli, 
Italy; J-L. Noël: European Respiratory Society, Lausanne, Switzerland; S. Orfanos: 2nd Dept of Critical Care, University of Athens Medical School, Attikon Hospital, Athens, Greece; P. Palange: Dipartimento Medicina Clinica, University La Sapienza, Rome, Italy; B. Schoenhofer: Dept of Pulmonary and Intensive Care Medicine, Klinikum Region Hannover, Krankenhaus Oststadt-Heidehaus, Hannover, Germany; T. Vassilakopoulos: 1st Dept of Pulmonary and Critical Care Medicine, University of Athens Medical School, Evangelismos Hospital, Athens, Greece; A. Simonds: Academic Unit of Sleep and Breathing, Royal Brompton and Harefield NHS Foundation Trust, London, UK.

\section{REFERENCES}

1 European Commission. Schengen - 26 Years of Borderless Europe. http://ec.europa.eu/unitedkingdom/press/frontpage/2011/1181_ en.htm Date last updated: June 13, 2011. Date last accessed: December 16, 2011.

2 European Commission. The Lifelong Learning Programme: Education and Training Opportunities for All. http://ec.europa.eu/education/ lifelong-learning-programme/doc78_en.htm Date last updated: September 12, 2011. Date last accessed: December 16, 2011.

3 Buckley JD, Addrizzo-Harris DJ, Clay AS, et al. Multisociety task force recommendations of competencies in pulmonary and critical care medicine. Am Rev Respir Crit Care 2009; 180: 290-295.

4 Bion JF, Barrett H. Development of care competencies for an international training programme in intensive care medicine. Intensive Care Med 2006; 32: 1371-1383.

5 Reisner-Senelar L. The birth of intensive care medicine: Bjorn Ibsen's records. Intensive Care Med 2011; 37: 1084-1086.

6 Reshetar RA, Norcini JJ, Mills LE, et al. The first decade of the American Board of Internal Medicine certification in critical care medicine: an overview of examinees and certificate holders from 1987 through 1996. Crit Care Med 2000; 28: 1191-1195.

7 Pronovost PJ, Angus DC, Dorman T, et al. Physician staffing patterns and clinical outcomes in critically ill patients: a systematic review. JAMA 2002; 288: 2151-2162.
8 Van Aken H, Mellin-Olsen J, Pelosi P. Intensive care medicine: a multidisciplinary approach! Eur J Anaesth 2011; 28: 313-315.

9 The European Parliament and the Council of the European Union. Directive 2005/36/EC of the European Parliament and of the Council of 7 September 2005 on the recognition of professional qualifications. Official Journal of the European Union 2005; L225: 22-142. Available from: http://eur-lex.europa. eu/LexUriServ/ LexUriServ.do?uri=OJ:L:2005:255:0022:0142:en:PDF

10 The CoBaTrICE Collaboration. Development of core competencies for an international training programme in intensive care medicine. Intensive Care Med 2006; 32: 1371-1383.

11 Artigas A, Vassilakopoulos T, Brochard L, et al. Respiratory Critical Care HERMES: a European core syllabus in respiratory critical care medicine. Breathe 2012; 8: 217-229.

12 European Society of Intensive Care Medicine. An International Competency Based Training Programme in Intensive Care Medicine-CoBaTrICE. www.cobatrice.org/en/index.asp Date last accessed: December 16, 2011

13 Loddenkemper R, Séverin T, Mitchell S, et al. Adult HERMES: criteria for accreditation of ERS European training centres in adult respiratory medicine. Breathe 2010; 7: 170-176.

14 Loddenkemper R, Séverin T, Eiselé J-L, et al. HERMES: a European core syllabus in respiratory medicine. Breathe 2006; 3: 59-70.

15 Gappa M, Noël J-L, Severin T, et al. Paediatric HERMES: a European syllabus in paediatric respiratory medicine. Breathe 2009; 5: 237-241.

16 Loddenkemper R, Haslam PL, Séverin $\mathrm{T}$, et al. European curriculum recommendations for training in adult respiratory medicine: 2nd report of the HERMES Task Force. Breathe 2008; 5: 80-93.

17 Gappa M, Noël J-L, Séverin T, et al. Paediatric HERMES: European Curriculum Recommendations for Training in Paediatric Respiratory Medicine. Breathe 2010; 7: 72-78.

18 Miller GE. The assessment of clinical skills/competence/ performance. Acad Med 1990; 65: S63-S67. 